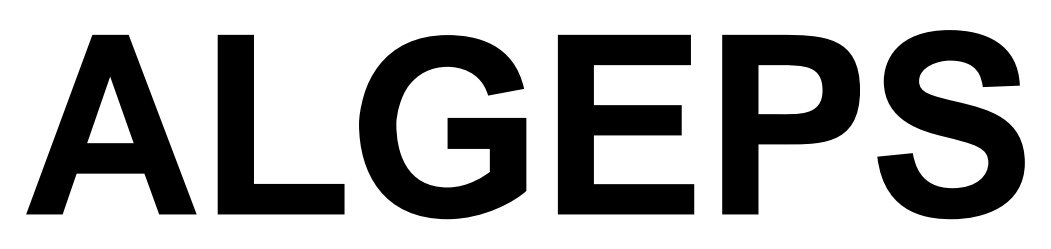

REVISTA DE GEOLOGIA, SĖRIE B no 585 - Març del 2012

ISSN $1132-7014$

D.L.B. 28.178 - 92

12 pàgines

\title{
RECORRIDO DESDE ALBELDA A CASTILLONROY, BALDELLOU Y CAMPORRELS, A TRAVÉS DEL PATRIMONIO GEOLÓGICO Y MINERO DE LAS COMARCA DE LA LITERA
}

Josep M. Mata-Perelló

Aquest recorregut va ésser experimentat amb docents el dia 7 DE JUNY DEL 2010 


\section{RECORRIDO DESDE ALBELDA A CASTILLONROY, BALDELLOU Y CAMPORRELS, A TRAVÉS DEL PATRIMONIO GEOLÓGICO Y MINERO DE LAS COMARCA DE LA LITERA}

\section{ADVERTENCIAS PREVIAS}

Como en otros recorridos de RECONOCIMIENTO GEOLÓGICO (o de RECONOCIMIENTO GEOLÓGICO Y MINERO), el recorrido se compondrá de diversas PARADAS. En este caso serán seis.

Por otra parte, habrá que tener en cuenta, en todo momento, especialmente antes de empezar los recorridos de los diferentes tramos, el estado de los caminos y carreteras, por donde transitará el recorrido. Al respecto, cabe decir que prácticamente todos estos tramos se halla en buenas condiciones.

Finalmente, como ya hacemos en otros recorridos similares, queremos decir que hace falta tener un cuidado muy especial en el respeto a la naturaleza, a lo largo de todo el recorrido del itinerario, y también fuera de él.

\section{BREVE INTRODUCCIÓN GEOLÓGICA}

Como en el caso del ITINERARIO GEOLÓGICO DE BINEFAR A ALINS, el recorrido de este itinerario, se desarrollará exclusivamente por la Depresión Geológica del Ebro (en sus tramos iniciales y centrales, desde Albelda hasta Baldellou) y por los Pirineos, (en los tramos finales del recorrido, entre la población antes mencionada y Camporrells).

Así, a lo largo de todo de todo el primer tramo del recorrido del itinerario (dentro de la Depresión Geológica del Ebro) se irán encontrando inicialmente afloramientos cenozoicos, en su mayoría de carácter arcilloso, yesoso y calcolutítico, pertenecientes al Oligoceno. Sin embargo, en los tramos finales, por lar cercanías de Baldellou se encontrará un importante paquete de conglomerados postorogénicos.

Luego, ya dentro del recorrido por los Pirineos, se irán encontrando afloramientos triásicos del Keuper (con niveles arcillosos y yesosos). Sin embargo, predominaran los afloramientos de los materiales carbonatados del Cretácico, dentro de los afloramientos pirenaicos de las Sierras Marginales, en el denominado Pirineo Meridional. Asimismo, a menudo, encontraremos afloramientos de los materiales detríticos cuaternarios, por encima de los anteriores 


\section{BREVE INTRODUCCIÓN GEOGRÁFICA}

En este caso, el recorrido del presente itinerario se efectuará exclusivamente por una sola comarca aragonesa, concretamente la de la Litera / Llitera. Así, el recorrido se iniciará se iniciará en la población de Albelda, para dirigirse luego hacía el NE, yendo primero hacía Castillonroy. El recorrido terminará en la población de Camporrells, en el límite NE de la comarca.

En este recorrido, se circulará por los términos municipales de: Albelda, Castillonroy, Baldellou y Camporrells, todos ellos de la comarca de la Litera / Llitera, en donde se habrá iniciado el recorrido.

Como es conocido, esta comarca, gravita en torno a dos ríos de la misma cuenca: el Noguera Ribagorzana que drena los sectores orientales y el Cinca que hace lo propio con los sectores occidentales. En cuanto al recorrido del itinerario, se halla totalmente situada dentro de la cuenca del primer río. De hecho, este río baña parte de los municipios por donde trascurrirá el recorrido

\section{OBJETIVOS GENERALES DE ESTE ITINERARIO}

En este itinerario, los objetivos generales que se han de conseguir, se pueden concretar en los siguientes aspectos:

1.- Estudio y reconocimiento de los materiales cenozoicos (en buena parte del Oligoceno y del Mioceno, según los lugares) situados en la Depresión Geológica del Ebro, que iremos encontrando a lo largo del recorrido del itinerario, entre la población de Albelda y la de Baldellou.

2.- Visión de algunas de las antiguas explotaciones encontradas a lo largo del recorrido del itinerario. En concreto de:

2A) de las explotaciones de yeso, situadas en el municipio de Albelda, entre los afloramientos cenozoicos.

2B) de las explotaciones de grava, situadas en el municipio de Albelda (aunque cerca de Castillonroy), junto a la carretera nacional $\mathrm{N}-230$.

2C) de algunas de las explotaciones de las rocas carbonatadas cretácicas, que encontraremos cerca de Baldellou.

3.- Observación del impacto producido por las actividades mineras. I si se da el caso, de las restauraciones realizadas para paliar este impacto.

4.- Visión de los diferentes lugares directamente relacionados con el Patrimonio Geológico y Minero que iremos encontrando a lo largo del recorrido del presente itinerario. Dentro del primero, veremos los congostos situados en el Barranco del Molí (entre Baldellou y Camporrells). Y dentro del segundo nos referimos a los hornos de cal de Camporrells. 


\section{ANTECEDENTES BIBLIOGRÁFICOS}

En relación con este itinerario, no conocemos ningún antecedente, relativo a otro itinerario que discurra por este lugar. En este sentido, este itinerario ya constituye un antecedente, si no estamos equivocados. Existen antecedentes en itinerarios cercanos nuestros: MATA - PERELLÓ (1990, 1991, 1996 t 2002); así como en MATA PERELLÓ y MONTANÉ GARCÍA (2002 y 2004). Aunque se trata de recorridos no coincidentes con el que ahora presentamos.

Por otra parte, haremos mención de algunos trabajos, de carácter geológico generalista, que corresponden a los trabajos del IGME (1972, 1974 y 1975), relativos al Mapa Geológico de España (a Escala 1.200.000), al Mapa Metalogenético de España y al Mapa de Rocas Industriales de España También cabe mencionar a GUIMERÁ et altri (1992), así como a RIBA et altri (1976).

Con respecto a las mineralizaciones que iremos encontrando, mencionaremos los trabajos de: CALVO et altri (1988); MAESTRE (1845); así como nuestros trabajos: MATA-PERELLÓ (1987 y 1998).

También mencionaremos el trabajo de PRAMES (2005) dedicado a la comarca del Campo de Belchite. Así como el del GOBIERNO DE ARAGÓN (2001), dedicado a los Puntos de Interés Geológico de Aragón.

Finalmente, diremos que todos estos trabajos (así como otros que ahora no hemos aludido), figurarán mencionados, por orden alfabético, en el apartado dedicado a las REFERENCIAS BIBLIOGRÁFICAS.

\section{RECORRIDO DEL ITINERARIO}

Este recorrido se iniciará en las inmediaciones de la población de Albelda, en donde se efectuará la primera parada. Tras ello, el recorrido se dirigirá hacía la cercana población de Castillonroy, continuando brevemente por la carretera nacional $\mathrm{N}-230$, con la finalidad de efectuar una nueva parada en una gravera situada a la izquierda de la carretera (dentro del término de Albelda).

Tras ello, se retornará a Castillonroy, con la finalidad de seguir ahora hacia Baldellou. En las inmediaciones del pueblo se efectuaran dos nuevas paradas. Luego, el recorrido continuará hacía Camporrells, en donde finalizará tras efectuarse nuevas paradas en las inmediaciones del mismo.

\section{DESCRIPCIÓN DEL ITINERARIO}

Como de costumbre, haremos una serio de PARADAS (o ESTACIONES), en donde se realizaran diversas explicaciones en torno a las características del lugar en donde se halla la PARADA. Por otra parte, en ellas haremos mención del término municipal dónde se encuentran, así como del número del "Mapa Topográfico Nacional (a escala 1:50.000, que indicaremos entre paréntesis. Así, ahora (en este recorrido) 
utilizaremos solamente tres hojas, concretamente las siguientes: 326 (o de Monzón) y 327 (o de Os de Balaguer). Así, la relación ordenada de las paradas que constituyen el recorrido de este itinerario, es la siguiente:

PARADA 1. YESERA Y YESERÍA, (término municipal de Albelda, comarca de la Litera / Llitera). (Hoja 326).

El recorrido del presente itinerario lo iniciaremos en la localidad de Albelda. Y más concretamente lo haremos en una antigua yesería, situada junto a la población, en una posición ligeramente septentrional.

Tanto la población de Albelda, como toda la zona, se halla ubicada en la Depresión Geológica del Ebro. Así, se observan afloramientos de los materiales cenozoicos por doquier. Estos materiales pertenecen a los tramos altos del Oligoceno. Así es fácil ver afloramientos de yesos, arcillas y calcolutitas, con abundantes paleocanales arenosos. En el lugar de la parada hay un afloramiento de los materiales yesosos que han sido explotados en una cantera cercana, en una yesera $\mathrm{Y}$ junto a ella se encuentra la yesería.

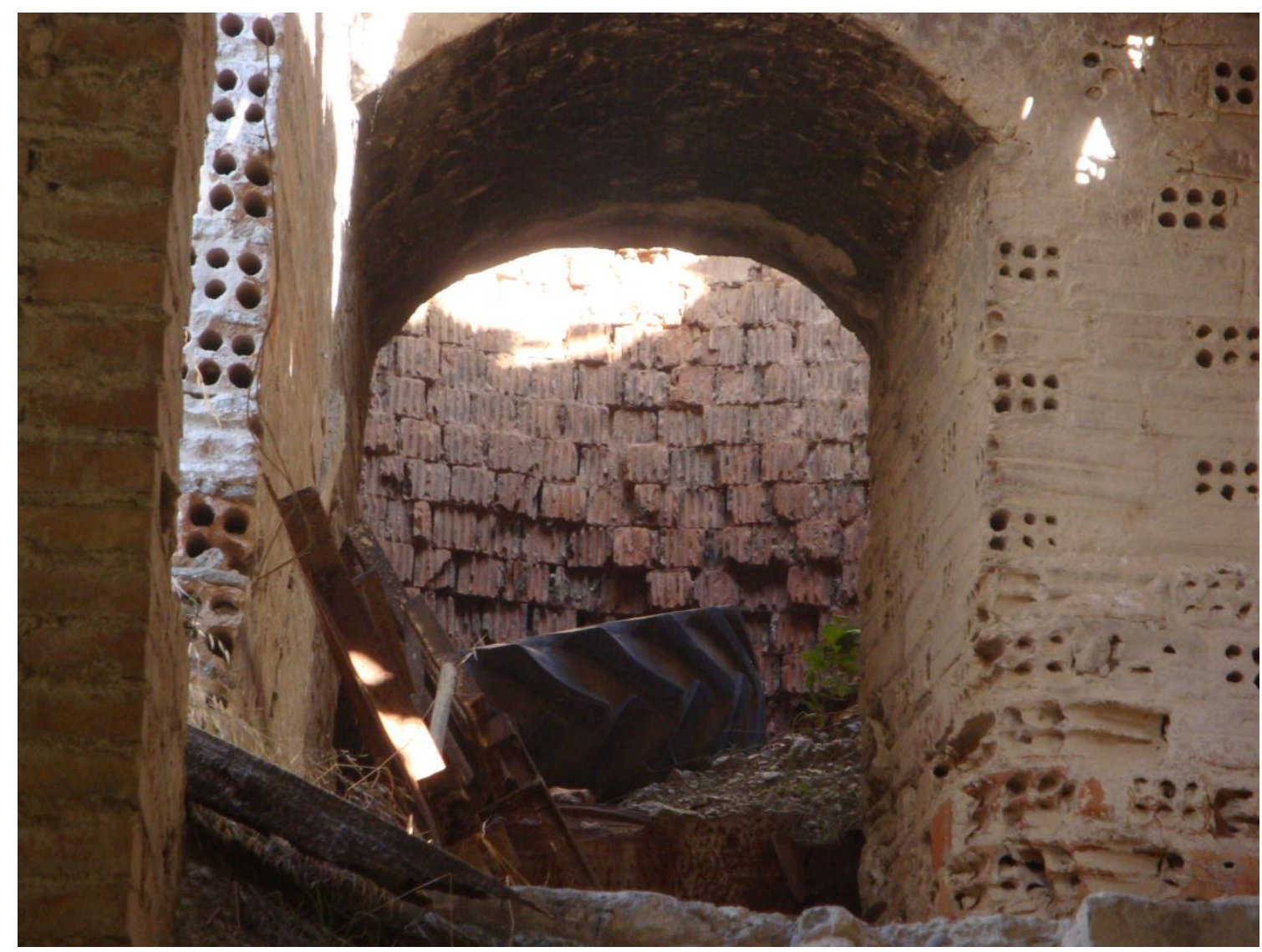

Horno de yeso de la yesería

Cabe decir que todo el conjunto se halla en muy mal estado de conservación. A pesar de ello, estos elementos forman parte del Patrimonio Minero de la comarca de la Litera. 
PARADA 2. GRAVERA DE LA CARRETERA $N$ - 230, (término municipal de Albelda, comarca de la Litera / Llitera). (Hoja 327).

Tras realizar la parada anterior, es necesario efectuar un recorrido de unos $6 \mathrm{Km}$ con la finalidad de llegar hasta las inmediaciones de Castillonroy, concretamente a la carretera nacional $\mathrm{N}-230$. Al llegar a ella, nos convendrá ir hacía el Norte, durante unos $3 \mathrm{Km}$, hasta llegar a una gravera (perteneciente al municipio de Albelda) situada a la izquierda de la carretera. Ahí efectuaremos una nueva parada, a unos $8-9 \mathrm{Km}$ de la anteriormente realizada.

En este recorrido, hemos ido encontrando, fundamentalmente, afloramientos de los materiales citados en la parada anterior. Esto es, niveles de yesos, calcolutitas yesosas. A veces hemos encontrado paleocanales arenosos.

Sin embargo, en el lugar de la parada, hemos encontrado importantes afloramientos de materiales detríticos de origen fluvial. Es decir una importante terraza fluvial con clastos poligénicos procedentes del paleozoico y del mesozoico. Sin embargo, no desciframos a que río puede pertenecer esta terraza.

En este lugar, hay una importante explotación de áridos, que actualmente se halla cerrada.

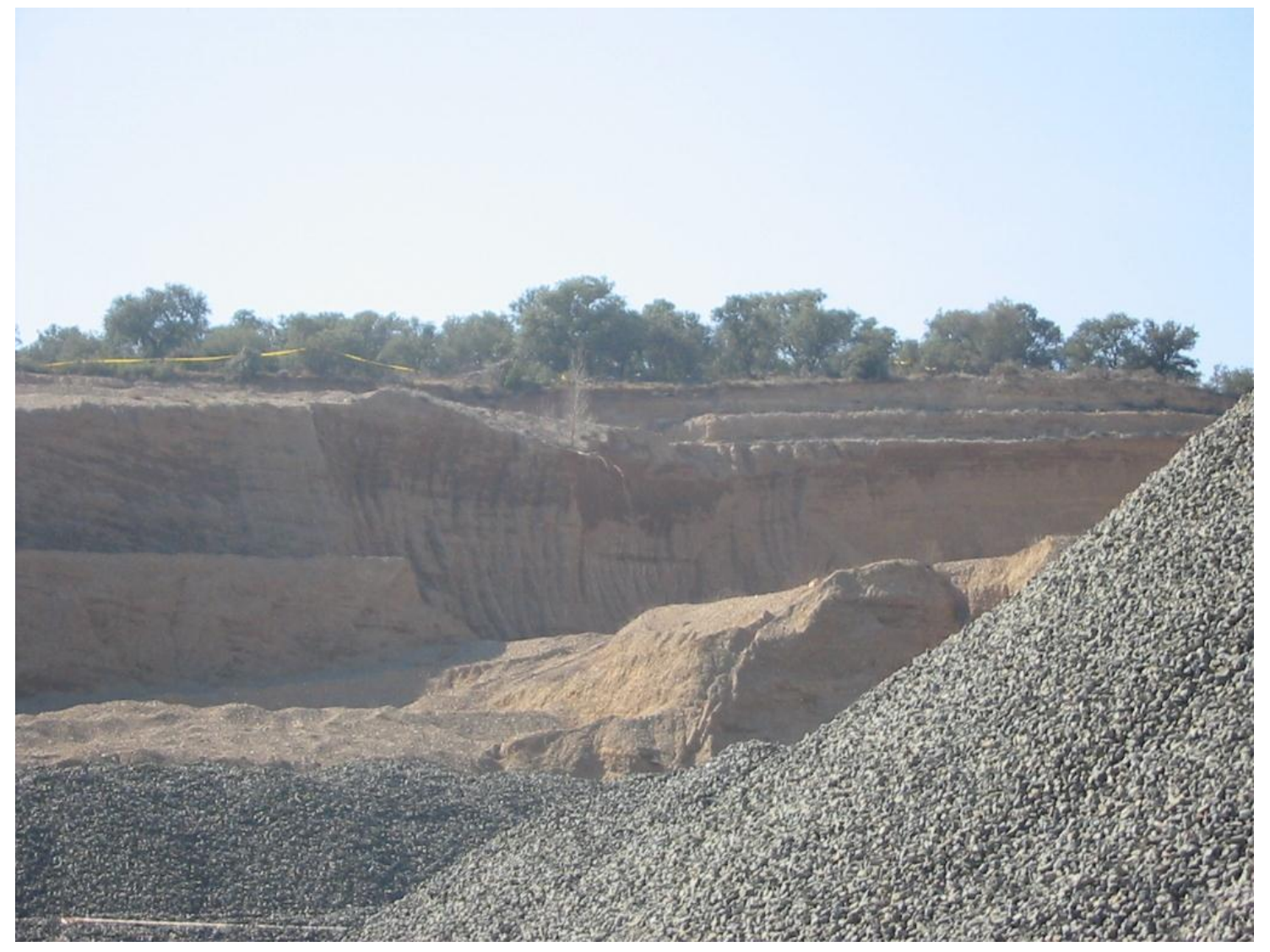

Gravera. Tiene el acopio de otra explotación cerca de ofitas (de Estopiñan del Castillo), de la misma empresa. 
A la vista de los materiales de la gravera, como ya hemos avanzado, nos surge una duda: a que río pertenece. El Noguera Ribagorzana está algo alejado del lugar. El torrente que pasa por las inmediaciones es incapaz de generar esta terraza. Una posibilidad sería la de que estos materiales pertenecieran al "viejo Esera". Podría ser que este río desembocara antes en el Conca (cerca de Fraga) o en el Segre (cerca de Serós), habiendo sido captado por el propio Cinca, cerca de Estada. Observando el gradiente de estos materiales detríticos cerca de Baells, se puede observar una relativa migración hacía el poniente.

PARADA 3. CANTERA DEL SOLÁ, (término municipal de Baldellou, comarca de la Litera / Llitera). (Hoja 327).

Después de realizar la parada anterior, conviene retornar a Castillonroy, para seguir luego por la carretera que conduce a Baldellou. Tras coronar el pequeño puerto que separa ambos pueblos, en el descenso encontraremos un camino por la derecha, que conduce en unos $3 \mathrm{Km}$ a la Cantera del Solá. Ahí haremos una nueva parada, a unos 12 $\mathrm{Km}$ de la anteriormente efectuada.

En este recorrido, habremos ido encontrando afloramientos de los materiales yesosos. Sin embargo, en el ascenso hacía Baldellou, habremos encontrado abundantes afloramientos de materiales detríticos. Éstos pertenecen al Oligoceno postorogénico, aunque también los hay de cuaternarios.

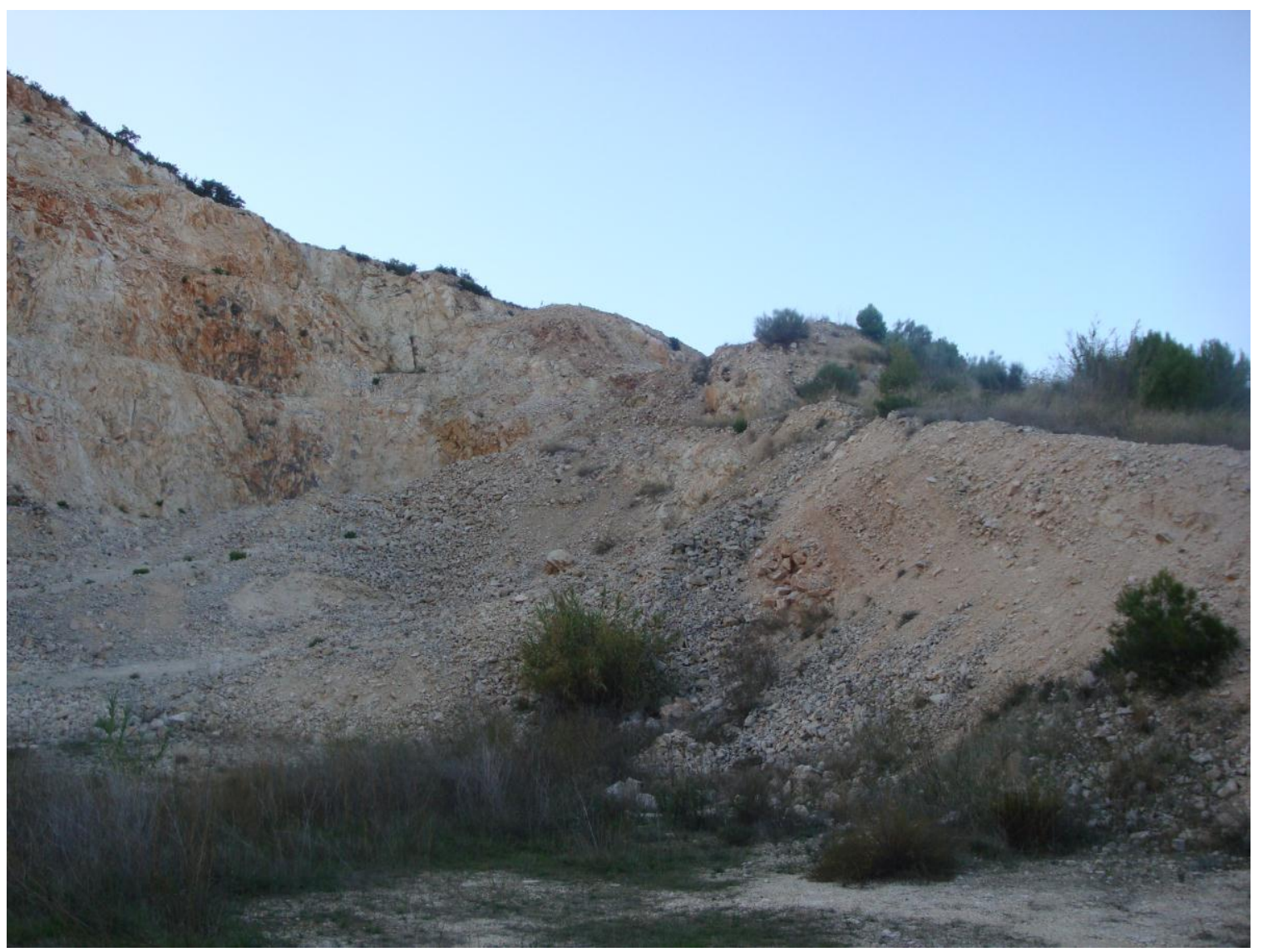

Cantera del Solá 
Sin embargo, al llegar al lugar de la parada, por debajo de los conglomerados oligocénicos hemos encontrado unos niveles carbonatados cretácicos. Estos son los materiales explotados en esta cantera, para ser utilizados como áridos para la construcción.

PARADA 4. BARRANCO DEL MOLÍ - 1 (PARTE BAJA), (término municipal de Baldellou, comarca de la Litera / Llitera). (Hoja 327).

Tras efectuar la parada anterior, cabe continuar por la carretera que conduce al cercano pueblo de Baldellou. Casi al llegar a él, se encontrará el camino (por la izquierda de la carretera) que conduce a la parte baja del Barranco del Molí. Nos convendrá ir por este camino, hasta la parte final a la que pueden llegar los vehículos. A partir de ahí convendrá seguir a pie unos 100 metros. En ese lugar efectuaremos una nueva parada, a unos $7 \mathrm{Km}$ de la anterior.

En este recorrido, desde Baldellou hasta el lugar de la parada, habremos ido encontrando afloramientos de los materiales carbonatados del Cretácico. Sobre estos materiales se ha ido encajando el Barranco del Molí, abriendo un bello congosto.

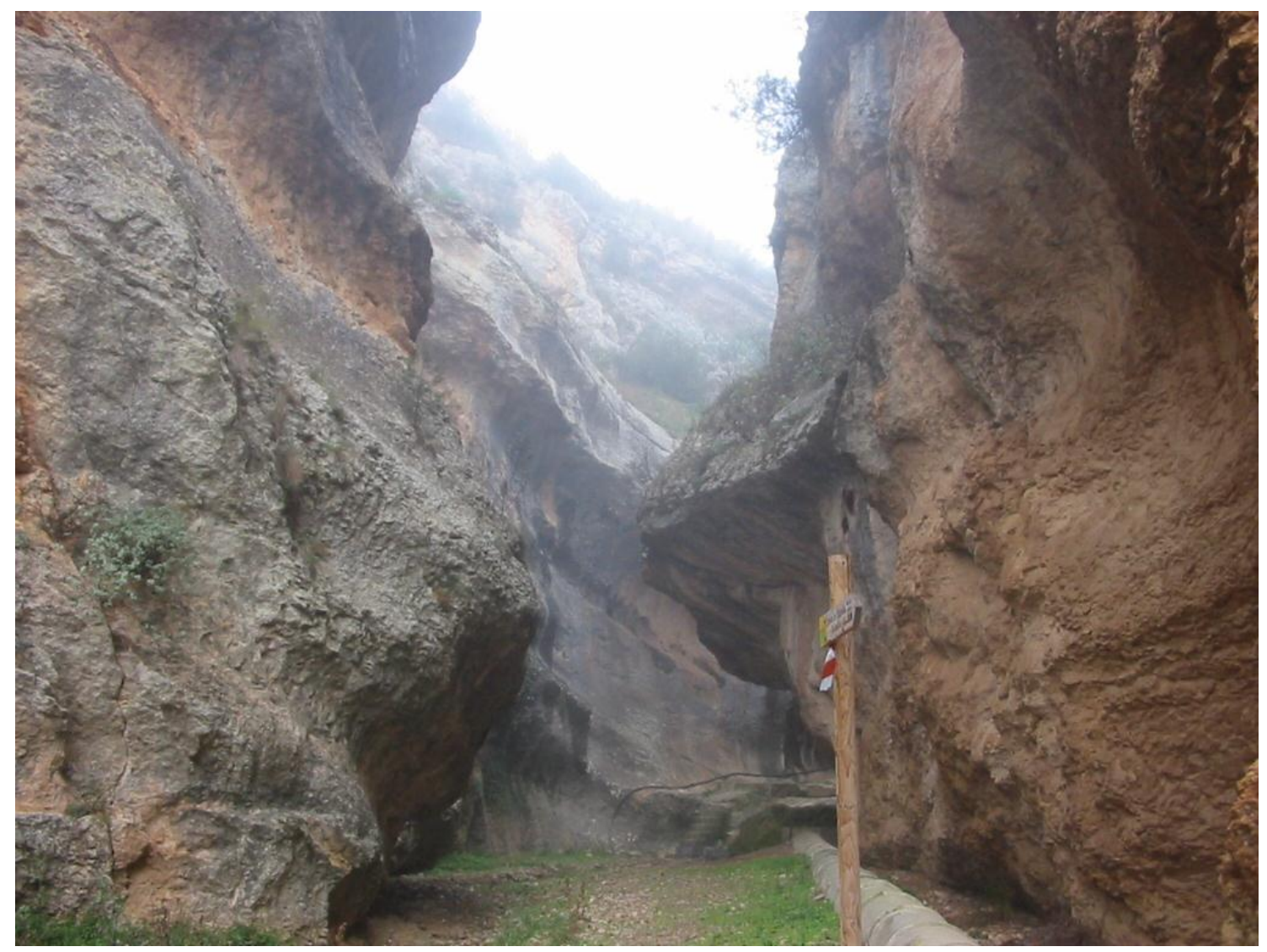

Un aspecto de la parte baja del Barranco del Molí

Este lugar (conjuntamente con el resto del congosto, que veremos a continuación) forma parte un interesante lugar del Patrimonio Geológico de la comarca de la Litera. Al respecto de ello, cabe decir que se halla perfectamente señalizado a lo largo de todo el recorrido. 
PARADA 5. BARRANCO DEL MOLÍ - 2, (PARTE ALTA), (término municipal de Camporrells, comarca de la Litera / Llitera). (Hoja 327).

Después de realizar la parada anterior, conviene retornar al pueblo de Baldellou. Luego será necesario continuar por la carretera que conduce a Camporrells. Al llegar de nuevo al Barranco del Molí, efectuaremos una nueva parada. Así, desde la anterior habremos recorrido en coche unos $5 \mathrm{Km}$. Si lo hubiéramos hecho a pie, habrían sido apenas 1'3 Km.

En este recorrido, hemos ido encontrando afloramientos de los materiales mesozoicos de las Sierras Marginales de los Pirineos. Sobre estos materiales se ha ido esculpiendo este bello congosto, que forma parte del Patrimonio Geológico de la comarca de la Litera.

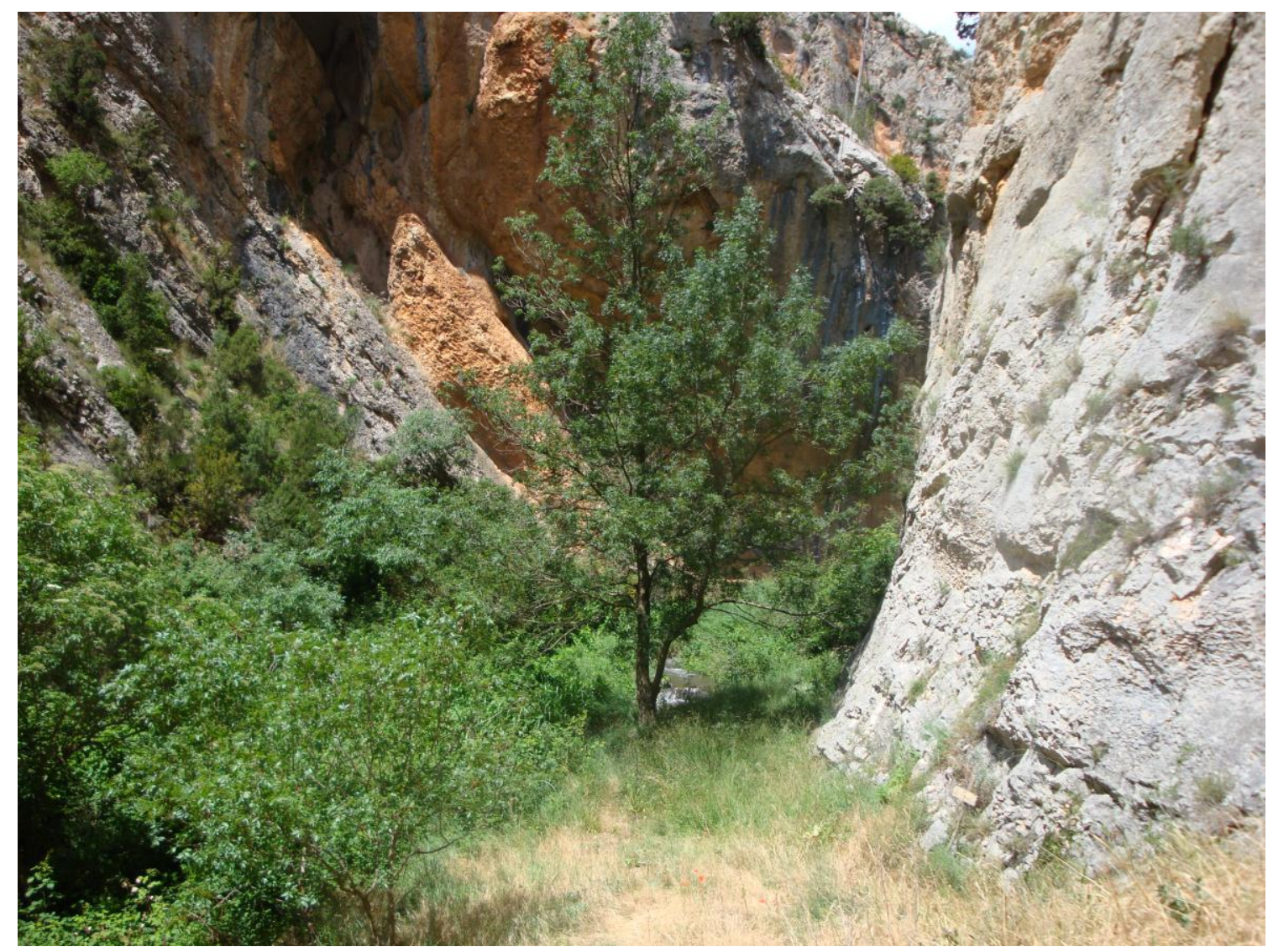

Parte alta del congosto, junto a la carretera de Camporrells

PARADA 6. ENTRADA A CAMPORRELLS, DESDE NACHÁ, (término municipal de Camporrells, comarca de la Litera - Llitera). (Hoja 327).

Tras efectuar la parada anterior, conviene efectuar un nuevo recorrido por la carretera que va conduciendo hasta el cercano pueblo de Camporrells. Al llegar a él y atravesarlo, nos convendrá ir hacía la entrada del pueblo, viniendo desde Nachá. Ahí, en las cercanías del viejo Pozo de Hielo, haremos una nueva parada, a unos $4 \mathrm{Km}$ más allá de la anterior. 
En este recorrido hemos ido encontrando afloramientos de los materiales citados en las paradas anteriores. Sin embargo, al llegar a Camporrells habremos encontrado afloramientos de los materiales triásicos del Keuper. Así, habremos visto afloramientos de yesos y también de ofitas, como en este lugar.

Aquí, entre los afloramientos de ofitas, se hacen patentes unas mineralizaciones azuladas. Se trata de la presencia de AERINITA. Cabe decir que este lugar bien podría considerarse como Patrimonio Geológico. Cabe decir que la fotografía con la que se encabeza este itinerario corresponde a l'AERINITA de Camporrells. Otra instantánea es:

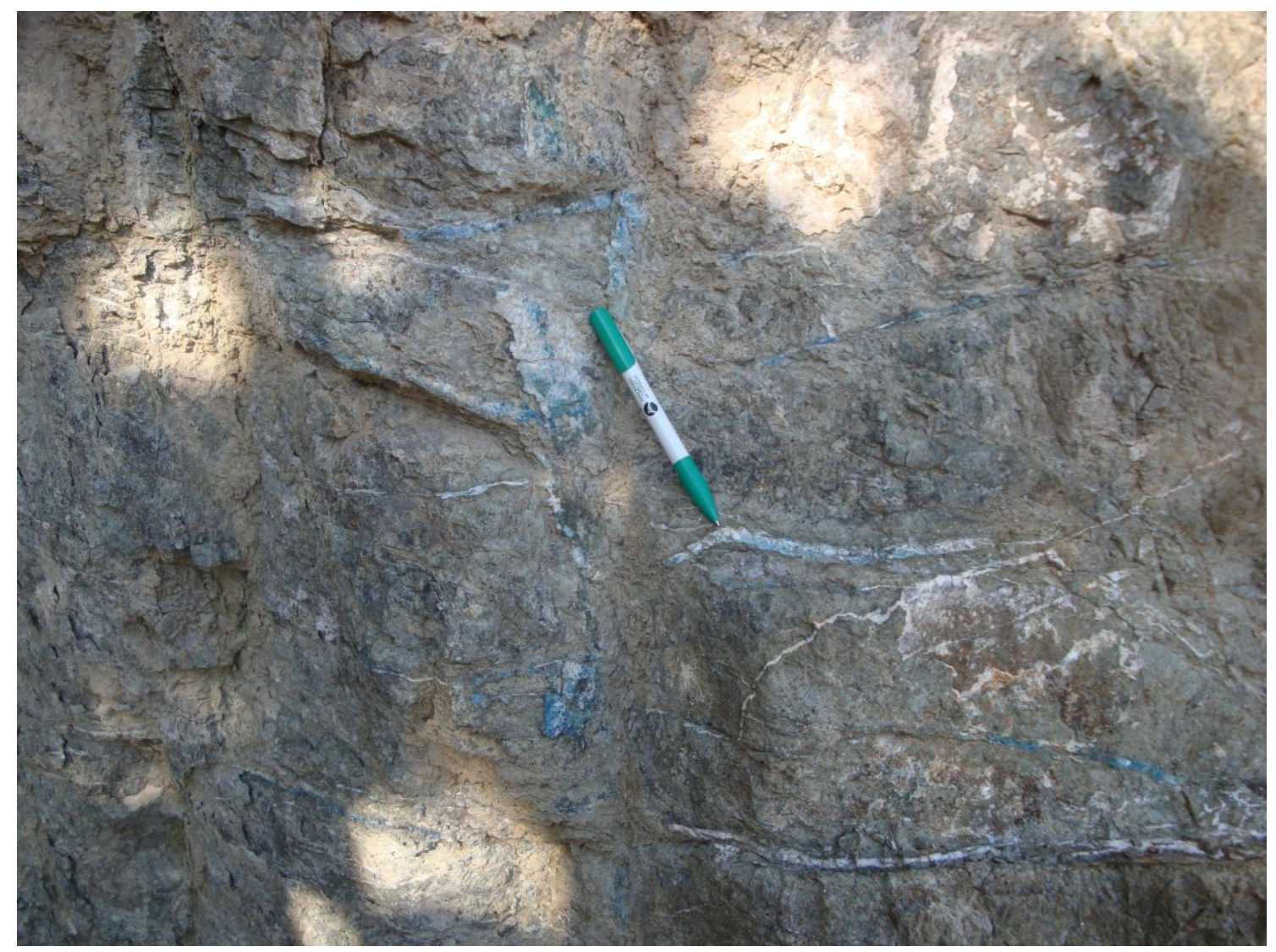

La AERINITA y las ofitas

\section{PARADA 7. HORNOS DE CAL DE LA CANTERA DE CALIZAS, (término municipal de Camporrells, comarca de la Litera / Llitera). (Hoja 327).}

Después de efectuar la parada anterior, conviene volver a atravesar el pueblo de Camporrells, para continuar ahora por la carretera que conduce a Estopiñan del Castillo (comarca de la Ribagorza, aunque antaño pertenecía a la Litera). A algo más de $1 \mathrm{Km}$ del pueblo efectuaremos una nueva parada, a la izquierda de la carretera, siendo esta la parada final del itinerario.

En este recorrido, hemos ido encontrando afloramientos de los materiales mesozoicos del Cretácico. Estos materiales se sitúan en las Sierras Marginales Pirenaicas. En este lugar han sido explotados en una vieja cantera ahora abandonada. 
De ella quedan como resto unos antiguos hornos de cal, que forman parte del Patrimonio Minero de la comarca de la Litera.

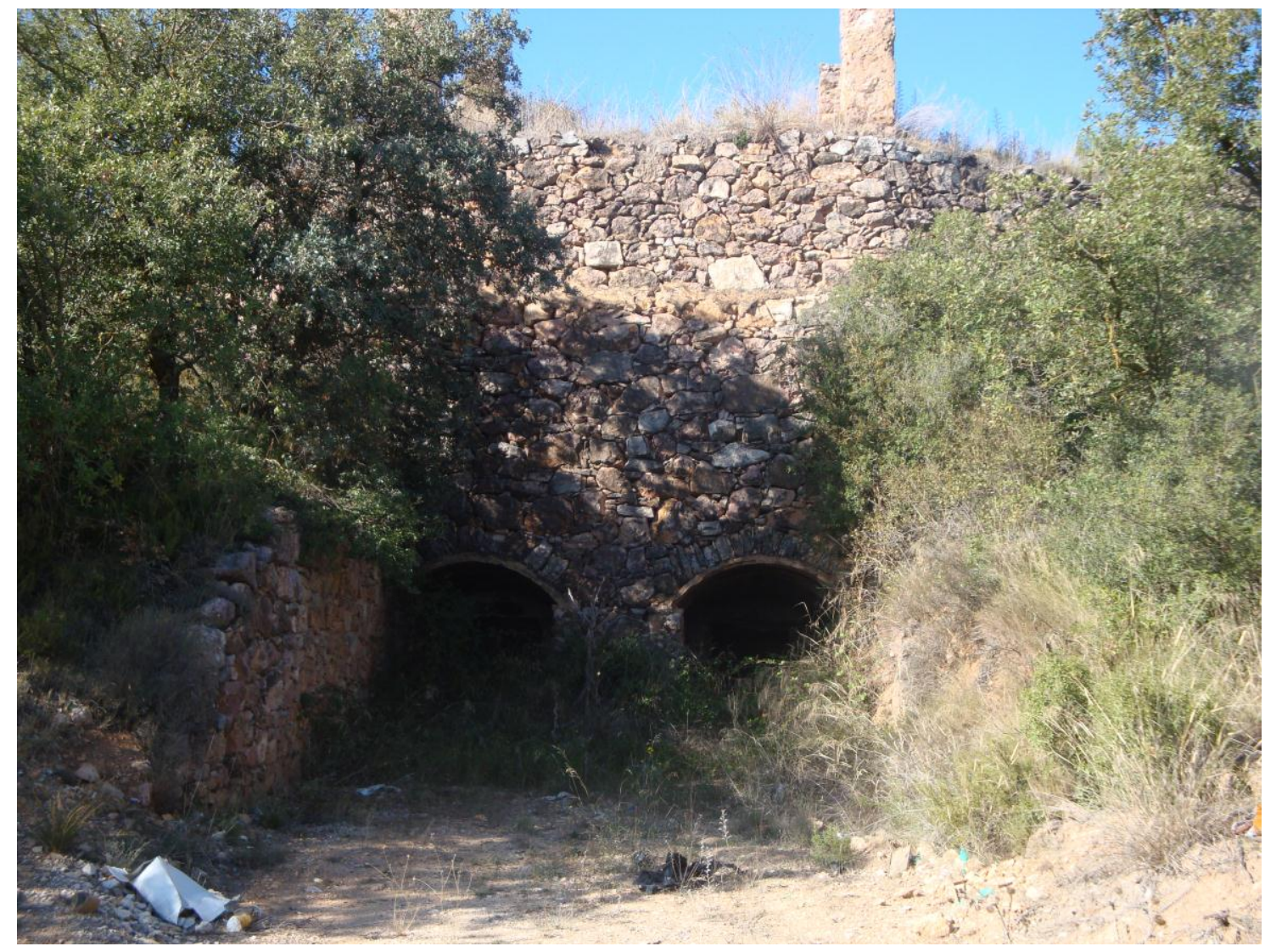

Hornos de cal de Camporrells

EN ESTE LUGAR FINALIZA EL ITINERARIO

\section{BIBLIOGRAFÍA}

CALVO, M. et altri (1988).- Minerales de Aragón. Colección Temas geológicos. 200 pag. Zaragoza

GOBIERNO DE ARAGÓN (2001).- Puntos de Interés Geológico de Aragón. Consejería de Medio Ambiente del Gobierno de Aragón. Zaragoza

GUIMERÀ, J. et altri (1992).- Geología (II), Historia Natural de los Países Catalanes, Volum.2, 547 pag. Enciclopèdia Catalana, S.A. Barcelona 
IGME (1972).- Mapa Geológico de España a escala 1:200.00 (Síntesis de la Cartografía existente). Hoja y memoria no 23 (Huesca). Inst. Geol. Min. España. Minist. Industria. Madrid

IGME (1974).- Mapa Metalogenético de España a escala 1:200.00. Hoja y memoria $\mathrm{n}^{\circ}$ 23 (Huesca). Inst. Geol.Min. España. Minist. Industria. Madrid

IGME (1975).- Mapa de Rocas Industriales de España a escala 1:200.00. Hoja y memoria no 23 (Huesca). Inst. Geol.Min. España. Minist. Industria. Madrid

MAESTRE, A. (1845).- Visita al Distrito Minero de Aragón y Cataluña, Anales de Minas, tomo III, 145 pag. Madrid

MALLADA, L. (1881).- Descripción física y geológica de la provincia de Huesca.Mem. Com. Mapa Geol. De España. Vol. 15. pp. 1 - 439. Madrid

MATA - PERELLÓ, J.; (1987).- Introducción al conocimiento de las mineralizaciones aragonesas. Mineralogistes de Catalunya, t.III, pp. 258-265. Barcelona

MATA - PERELLÓ, J.M. (1990).- Inventario Mineralógico de la Región del Cinca (sectores Orientales). Rodeno, 19. 36 pag. Manresa

MATA-PERELLÓ, J.M. (1991).- Selección de Itinerarios de recerca mineralógica: por la Noguera, la Litera / Llitera i la Baja Ribagorza / Baixa Ribagorça. Xaragall, 27, 36 pag. Manresa

MATA-PERELLÓ, J.M. (1996).- Recerca geològica i mineralògica per les comarques del Segrià, Noguera, Litera / Llitera y Baja Ribagorza / Baixa Ribagorça: des d'Alfarràs a Peralta de la Sal, por Estopiñan / Estopanyà. Inédito, 10 pág. Manresa

MATA-PERELLÓ, J.M. (2002).- Recorregut de recerca geològica i mineralògica per les comarques del Segrià, de la Litera / Llitera i de la Baja Ribagorza / Baixa Ribagorça: des d'Alfarràs a Purroi y en Benabarre, revista Xaragall serie $\mathrm{B}, \mathrm{n}^{\circ}$ 236, 12 pag. Manresa

MATA-PERELLÓ, J.M. i MONTANÉ GARCÍA. P. (2002).- Recorregut de recerca geològica i mineralògica per les comarques del Segrià, la Litera / Llitera i la Baja Ribagorza / Baixa Ribagorça: des d’Alfarràs a Camporrells, a Caladrones / Caladrons i a Benabarre, Inédito, 14 pag. Manresa

MATA-PERELLÓ, J.M. i MONTANÉ GARCÍA. P. (2004).- Recorregut de recerca geològica i mineralògica per les comarques del Segrià, la Litera / Llitera i la Baja Ribagorza / Baixa Ribagorça: des d'Alfarràs a Estopiñan / Estopanyà i a Benabarre, Inédito, 14 pag. Manresa

MATA-PERELLÓ, J.M. i SANZ BALAGUÉ, J. (1989).- Inventari Mineralògic de la comarca de la Litera / Llitera. Revista Tierra Endins, nº 2, 32 pag. Manresa

PRAMES (2005).- Campo de Belchite. Colección RUTASCAL por Aragón. Prames, Gobierno de Aragón. 119 pag. Zaragoza. 